\title{
A Game Analysis of the Farmer Cooperatives' Joint Development
}

\author{
Wang Peng ${ }^{1,2}$ \\ 1. Business School, Hohai University, NanJing, P.R. China \\ 2. All China Federation of Supply and Marketing Cooperatives, BeiJing, P.R. China
}

\begin{abstract}
Joint development among farmers cooperatives is an inevitable trend. This paper, based on analysis of the game model, maintains that sound development of the federations of farmers cooperatives requires greater efforts into propaganda and education on cooperatives, strengthening of policy-based supply, support and guidance, optimization of the supervision and restriction mechanism, and rationalization of profit distribution mechanism among members.
\end{abstract}

\section{INTRODUCTION}

Since the enforcement of Law of the People's Republic of China on Specialized Farmers Cooperatives in 2007, China's farmers cooperatives have boomed, nowadays attaching greater importance to quality enhancement than increase in number. There is an increasing practical demand for farmers cooperatives to form federations and promote common development. The revised Law of the People's Republic of China on Specialized Farmers Cooperatives in 2017, in line with the trend of unification and cooperation among farmers cooperatives, comprises an exclusive chapter for the federations of farmers cooperatives, which serves as a legal norm for their establishment. Currently the federations of farmers cooperatives in China remain in the primary stage. It is imperative to grasp the objective laws of their development and identify their driving forces and obstacles so as to guide and promote their sound and standardized development.

\section{The INEVITABLE TREND OF UNIFICATION AND COOPERATION AMONG FARMERS COOPERATIVES}

\subsection{The unification and cooperation among farmers cooperatives conforms to the objective economic laws}

The transition to unification is an inevitable trend for farmers cooperatives ${ }^{[1]}$. Their vertical integration is favorable to boost production and expand market share ${ }^{[2]}$, while their horizontal unification would help form regional comprehensive and advanced cooperatives, covering each aspect of peasant life within a certain region ${ }^{[3]}$. Cooperatives are in essence a governance structure which maximizes the difference between external transaction costs saved and internal transaction costs incurred (governance costs) ${ }^{[4]}$. It is widely assumed in previous research that establishing the federations of farmers cooperatives are favorable for the prevention of homogeneous and vicious competition, realization of economies of scale and scope, and decrease in transaction costs.

\subsection{The unification and cooperation among farmers cooperatives conforms to their laws of development in practice}

Experience can be drawn from the unification and cooperation of cooperatives implemented abroad. American cooperatives within the same business scope have mostly evolved into nationwide federations, for instance, dairy farmers' cow marketing cooperatives. Germany cooperatives encompass, based on their business scopes, rural commodity and service, consumption, and housing cooperatives from central authorities to local and to grassroots. In Japan, a three-level bottom-up network has been established, composed of grassroots, countylevel, and national farmers cooperatives. Both the Mondragon cooperative association in Spain and Bulgarian consumption cooperative association demonstrate the law that cooperatives are bound to unify and cooperate to promote development.

\subsection{The joint development of farmers cooperatives is subject to the needs of both their members and market competition}

Experience can be drawn from the unification and cooperation of cooperatives implemented abroad. American cooperatives within the same business scope have mostly evolved into nationwide federations, for instance, dairy farmers' cow marketing cooperatives. Germany cooperatives encompass, based on their business 
scopes, rural commodity and service, consumption, and housing cooperatives from central authorities to local and to grassroots. In Japan, a three-level bottom-up network has been established, composed of grassroots, countylevel, and national farmers cooperatives. Both the Mondragon cooperative association in Spain and Bulgarian consumption cooperative association demonstrate the law that cooperatives are bound to unify and cooperate to promote development.

Comprehensive analysis shows that the unification and cooperation among cooperatives, a development trend that is subject to both external and internal factors, requires government support and guidance at this stage.

\section{Proposition of the Game Model for FARMERS COOPERATIVES' COOPERATION}

Farmers cooperatives, registered as legal persons of specialized farmers cooperatives in business administration department, are entities enjoying equal rights in market economy and normally compete with others operating in the same region. Decision making simply based on the rationality of individual cooperative will inevitably get the unification and cooperation mired in difficulties, ending up with failures or low efficiency. The following presents a game model for the joint development of farmers cooperatives built based on the utility function of the cooperation among organizations proposed by Sheng Zhaohan et al. ${ }^{[5]}$.

Suppose that there is a federation composed of two farmers cooperatives 1 and 2, whose willingness to cooperate expressed according to their own interests is recorded as $\mathrm{p}_{\mathrm{i}} \in[0,1], \mathrm{i}=1,2\left(\mathrm{p}_{\mathrm{i}}=1\right.$ means full cooperation, whereas $\mathrm{p}_{\mathrm{i}}=0$ represents no cooperation). Full cooperation refers to simultaneous occurrence of resource sharing and devotion to operation, while no cooperation signifies the opposite. Suppose that $U_{i}\left(p_{i}, p_{j}\right), i, j=1,2, j \neq i$, the utility function of farmers cooperative $i$, is a concave function of the degree of willingness to cooperate $\mathrm{p}_{\mathrm{i}}$ and meanwhile an increasing function of $\mathrm{p}_{\mathrm{j}}$, namely $\partial^{2} \mathrm{U}_{\mathrm{i}}\left(\mathrm{p}_{\mathrm{i}}, \mathrm{p}_{\mathrm{j}}\right) / \partial \mathrm{p}^{2}{ }_{\mathrm{i}}<0$, and $\partial \mathrm{U}_{\mathrm{i}}\left(\mathrm{p}_{\mathrm{i}}, \mathrm{p}_{\mathrm{j}}\right) / \partial \mathrm{p}_{\mathrm{j}}>0$. Economically speaking, the former means diminishing marginal utility of cooperation, and the latter higher utility gained due to the other party's higher willingness to cooperate. Suppose the utility function of the farmers cooperative is:

$$
U_{i}\left(p_{i}, p_{j}\right)=B_{i}\left(p_{i}, p_{j}\right)-C_{i}\left(p_{i}\right)
$$

wherein $B_{i}\left(p_{i}, p_{j}\right)$ that represents $i$ 's revenue is an increasing function of $\mathrm{p}_{\mathrm{i}}$ and $\mathrm{p}_{\mathrm{j}}$, and meanwhile a concave function of $\mathrm{p}_{\mathrm{i}}$; $\mathrm{C}_{\mathrm{i}}\left(\mathrm{p}_{\mathrm{i}}\right)$ that represents $\mathrm{i}$ 's costs is both an increasing and convex function of $\mathrm{p}_{\mathrm{i}}$, namely increasing marginal cost of cooperation.

$\mathrm{B}_{\mathrm{i}}\left(\mathrm{p}_{\mathrm{i}}, \mathrm{p}_{\mathrm{j}}\right)$ and $\mathrm{C}_{\mathrm{i}}\left(\mathrm{p}_{\mathrm{i}}\right)$ may set as:

$B_{i}\left(p_{i}, p_{j}\right)=a_{i} p_{i}+b_{i} p_{j}+c_{i} p_{i} p_{j}, a_{i}>0, b_{i}>0, c_{i}>0$;

$\mathrm{C}_{\mathrm{i}}\left(\mathrm{p}_{\mathrm{i}}\right)=1 / 2 \mathrm{~d}_{\mathrm{i}} \mathrm{p}^{2} \mathrm{i}, \mathrm{d}_{\mathrm{i}}>0$

wherein $a_{i}$ represents $i$ 's utility in the situation where $i$ fully cooperates but the other farmers cooperative $j$ completely reject cooperation (for instance, business results yielded alone); $b_{i}$ represents i's utility in the situation where j fully cooperates but i completely reject cooperation (for instance, the free rider arising from higher brand awareness of the federation in the region); $\mathrm{c}_{\mathrm{i}}$ represents the cross utility generated by $\mathrm{i}$ when these two farmers cooperatives both fully cooperate (for example, business results achieved by jointly carrying out goods and services exhibition and other cooperative programs). No utility is generated when both cooperatives completely reject cooperation. $\mathrm{d}_{\mathrm{i}} / 2$ represents the costs when $\mathrm{i}$ fully cooperates. Generally i's costs incurred during cooperation is greater than cross utility if $c_{i} \leq d_{i} / 2$, namely full cooperation.

In consequence, the utility function of farmers cooperative $\mathrm{i}(\mathrm{i}=1,2)$ is:

$$
U_{i}\left(p_{i}, p_{j}\right)=a_{i} p_{i}+b_{i} p_{j}+c_{i} p_{i} p_{j}-1 / 2 d_{i} p^{2}{ }_{i}
$$

Suppose that $\mathrm{i}$ and $\mathrm{j}$ simultaneously operate and i's willingness to cooperate is $\mathrm{P}_{\mathrm{i}}$.

In the following model, since the second order condition of farmers cooperative 1 is apparently satisfied, the solution meeting the following first order condition will be the optimum solution:

$$
\partial \mathrm{U}_{1}\left(\mathrm{p}_{1}, \mathrm{p}_{2}\right) / \partial \mathrm{p}_{1}=\mathrm{a}_{1}+\mathrm{c}_{1} \mathrm{p}_{2}-\mathrm{d}_{1} \mathrm{p}_{1}=0
$$

Reaction function obtained by solving equation (3) is:

$$
\mathrm{p}_{1}\left(\mathrm{p}_{2}\right)=\mathrm{a}_{1} \mathrm{~d}_{1}^{-1}+\mathrm{c}_{1} \mathrm{~d}_{1}^{-1} \mathrm{p}_{2}
$$

Equation (4) demonstrates that a higher willingness to cooperate shown by farmers cooperative 2 is accompanied by higher optimum reaction of cooperative 1 . The optimum reaction function of cooperative 2 can be obtained similarly:

$$
\mathrm{P}_{2}\left(\mathrm{p}_{1}\right)=\mathrm{a}_{2} \mathrm{~d}_{2}^{-1}+\mathrm{c}_{2} \mathrm{~d}_{2}^{-1} \mathrm{p}_{1}
$$

Simultaneous equations (4) and (5) can be solved:

$$
\mathrm{p}^{*}{ }_{1}=\left(\mathrm{a}_{1} \mathrm{~d}_{1}^{-1}+\mathrm{a}_{2} \mathrm{C}_{1} \mathrm{~d}_{1}{ }^{-1} \mathrm{~d}_{2}{ }^{-1}\right) /\left(1-\mathrm{C}_{2} \mathrm{C}_{1} \mathrm{~d}_{1}{ }^{-1} \mathrm{~d}^{2}{ }_{-1}\right)
$$$$
\mathrm{p}_{2}^{*}=\left(\mathrm{a}_{2} \mathrm{~d}_{2}^{-1}+\mathrm{a}_{1} \mathrm{c}_{2} \mathrm{~d}_{1}^{-1} \mathrm{~d}_{2}^{-1}\right) /\left(1-\mathrm{c}_{1} \mathrm{c}_{2} \mathrm{~d}_{1}^{-1} \mathrm{~d}_{2}{ }^{-1}\right)
$$

Since $\mathrm{c}_{\mathrm{i}} \leq \mathrm{d}_{\mathrm{i}} / 2$, so $1-\mathrm{c}_{1} \mathrm{C}_{2} \mathrm{~d}_{1}{ }^{-1} \mathrm{~d}_{2}{ }^{-1}>0$. $\mathrm{p}^{*}{ }_{1}>0$ and $\mathrm{p}_{2}{ }_{2}>$ 0 . Therefore, these two cooperatives' optimum degrees of willingness to cooperate, which must be smaller than 1 , are respectively:

$$
\mathrm{p}^{* *}{ }_{1}=\min \left\{1, \mathrm{p}_{1}^{*}\right\}, \mathrm{p}^{* *}{ }_{2}=\min \left\{1, \mathrm{p}_{2}^{*}\right\}
$$

\section{Parameter Analysis of the Game MODEL FOR FARMERS COOPERATIVES' COOPERATION}

It follows from the above analysis that the optimum degree of willingness to cooperate shown by regional farmers cooperatives is subject to the influence of the parameters $a_{i}, b_{i}, c_{i}$, and $d_{i}(i=1,2)$. The following, based on comparative static analysis, discusses the influence imposed by parametric variation on the equilibrium solution of cooperatives' optimum degree of willingness to cooperate.

\subsection{Parameters $d 1$ and $d_{2}$}

It is proved that $\partial \mathrm{p}_{1}{ }_{1} / \partial \mathrm{d}_{1}<0, \partial \mathrm{p}^{*}{ }_{1} / \partial \mathrm{d}_{2}<0, \partial \mathrm{p}_{2}{ }_{2} / \partial \mathrm{d}_{1}<0$ and $\partial \mathrm{p}_{2}{ }_{2} / \partial \mathrm{d}_{2}<0$, indicating that these two cooperatives' optimum degrees of willingness to cooperate both increase as costs incurred during cooperation decrease. The cooperative costs of farmers cooperatives in a region are principally incurred by information blockade due to their sectionalism, a situation in which the transaction costs between any farmers cooperative and another in the same federation even exceed those incurred between it and other external market entities. In China, traditional 
awareness of small-scale peasant economy remains inveterate, while the value of putting the interests of an individual family, clan and small collective first pervades. Distrust and precaution of strangers and outside groups exist, and suspicions of and hostility to matters of relevance to the federations of cooperatives are common. Farmers are concerned about the likelihood of "failure to survive" and "suffering unfair losses". It is common to withdraw information and boycott resource sharing in the primary stage to determine whether to jointly establish and participate in a federation. Members of the federation might have conflicts of interest, benefit themselves at others' expense, and act willfully, compounding the difficulty in coordinate different cooperatives.

\subsection{Parameters c1 and $c_{2}$}

It is proved that $\partial \mathrm{p}_{1}{ }_{1} / \partial \mathrm{c}_{1}>0, \partial \mathrm{p}_{1}{ }_{1} / \partial \mathrm{c}_{2}>0, \partial \mathrm{p}_{2}^{*} / \partial \mathrm{c}_{1}>0$, and $\partial \mathrm{p}_{2}^{*} / \partial \mathrm{c}_{2}>0$, meaning that these two cooperatives' optimum degrees of willingness to cooperate both increase as the cross utility generated by their full cooperation rise. The increase in cross utility mainly depends on various complementary resources and business activities between the two sides. The key is to establish a set of internal rules to boost efficient cooperation in the federations of farmers cooperatives. Sound systems and rules have profound impacts on the effects of cooperation among cooperatives. For instance, Bulgarian consumption cooperative association formulates and implements the same policies in line with changes in external environment so as to regulate and coordinate operation, and enhance members' confidence and efficiency ${ }^{[6]}$. China's farmers cooperatives remain in the initial stage during which internal rules of cooperation in federations are still not as sound as expected. Some cooperatives bully the small and weak, and infringe farmers' rights in the process of unification, while other federations dominate during making business decisions ${ }^{[7]}$, which considerably dent farmers' enthusiasm for the unification and cooperation among farmers cooperatives.

\subsection{Parameters b1 and $b_{2}$}

It can be proved that $\partial \mathrm{p}_{1}^{*} / \partial \mathrm{b}_{1}=0, \partial \mathrm{p}_{1}^{*} / \partial \mathrm{b}_{2}=0, \partial \mathrm{p}_{2}^{*} /$ $\partial \mathrm{b}_{1}=0$, and $\partial \mathrm{p}_{2}^{*} / \partial \mathrm{b}_{2}=0$, indicating that these two cooperatives' optimum degrees of willingness to cooperate are unrelated to one party's utility when it rejects cooperation but the other party fully cooperates. $b_{1}$ and $b_{2}$ can be construed as the phenomenon of "free riding" occurring in operation and cooperation. Farmers cooperatives, which tend to behave like rational economic persons, expect to benefit as "free riders" from internal credit policies for cooperation, network platforms shared by all, and unified legal and tax services provided by federations they participate in. The unification and cooperation among cooperatives must be implemented on the basis of commensurate benefits for a certain quantity of costs. In practice, nevertheless, each member of any farmers cooperative is a institutional trader that normally concentrates on pursuing its own realistic and future benefits. Lack of supervision and restriction mechanisms might fail to prevent opportunistic behaviors and evasion of costs.

\subsection{Parameters a1 and $\mathrm{a}_{2}$}

It is apparent that $\partial \mathrm{p}^{*}{ }_{1} / \partial \mathrm{a}_{1}>0, \partial \mathrm{p}^{*}{ }_{1} / \partial \mathrm{a}_{2}>0, \partial \mathrm{p}_{2}{ }_{2} / \partial \mathrm{a}_{1}>$ 0 , and $\partial \mathrm{p}_{2}^{*} / \partial \mathrm{a}_{2}>0$, which indicates that these two cooperatives' optimum degrees of willingness to cooperate rise with the increase of utility generated when they themselves fully cooperate. The corresponding utility mainly comprises: complementary services and business scope, enhancement of regional brand awareness, and improvement of competence in regional market. The most fundamental and essential relations among farmers cooperatives are of relevance to interests. Smooth operation of interest coordination mechanism facilitates the development of relations between them; failing that, the reinforcement of their relations will be retarded. Winwin sharing during distributing economic benefits among cooperatives in a federation and scientifically efficient mechanisms of benefit compensation can enhance their enthusiasm.

\section{CONCLUSIONS AND DISCUSSIONS}

Based on the above parametric analysis, this paper maintains that satisfying results during cooperation among farmers cooperatives can be achieved by taking the following measures:

\subsection{To put greater efforts into propaganda and education on cooperatives and improve each member's cognition}

Among the seven internationally agreed principles for cooperatives is the principle of education, training, and information, which aims to publicize theories of cooperatives and effectively boost their development. Worldwide experience proves that widespread education on cooperatives conducted by government in the primary stage of cooperatives helps improve farmers' awareness of cooperation, laying a solid foundation for subsequent sound and sustainable development. China's cooperation movement and traditional ideas of small-scale peasant economy during its planned economy exert an impact on cooperatives' development to a certain extent. The government should spread theories and knowledge about cooperatives, and promote inclusive education and training. Members should gain a better understanding of the cooperatives, including tenets, missions, general principles, rules of operation and management, development trend, the relationship between members and cooperatives, between cooperatives and federations, as well as between cooperatives and agriculture, and one's own rights and obligations, so as to improve peasants' enthusiasm about cooperatives, reduce operational costs, and boost the development of farmers cooperatives and federations. 


\subsection{To strengthen policy-based supply, support and guidance}

Currently Law of the People's Republic of China on Specialized Farmers Cooperatives remains the sole law for cooperatives in China. The newly added chapter for the federation of farmers cooperatives in the revised version of 2017 simply specifies some general principles, which is insufficient to meet practical needs arising from thriving federations of cooperatives. The government needs to research and issue special laws as a further step to stipulate specific procedures and requirements of the unification and cooperation among cooperatives and internal major decision-making mechanisms, to make internal rules of operation meet standards. Moreover, authorities should boost sound development of the federations of farmers cooperatives by providing more preferential policies concerning finance, credit and tax for them, redoubling support in terms of scientific research and development, marketing, and technical popularization, and guiding farmers cooperatives and federations to operate in line with standards.

\subsection{To attach great importance to optimizing federations' supervision and restriction mechanisms}

The behavior of "free riding" that any farmers cooperative benefit from will not enhance its willingness to cooperate. To eliminate opportunistic behaviors during the unification and cooperation, attention must be paid to formulating binding supervision and restriction mechanisms in federations, specifying corresponding obligations in case of violation of cooperation rules, and ensuring their collaboration in resource provision, behaviors, and efforts required for federations' operation, on the premise of causing no damage to common interests. Costs must be shared on the basis of each member's affordability and meanwhile in line with the principle of cost-benefit balance so that those benefiting most and earlier bear more costs and initial ones respectively.

\subsection{To rationalize profit distribution mechanism among members of federations}

Only when the distribution of business incomes gained through joint operation reflects each party's interest demand, can members of the federation sincerely cooperate with each other on the basis of mutual trust and self-motivation. In consequence, special importance must be attached to the establishment of internal benefit sharing and compensation mechanisms in the federations of farmers cooperatives. First of all, distributable surplus of the federation should be refunded in accordance with the proportion of transaction volume between cooperative members and the federation. Additionally, it is essential to quantify member's share of the federation's assets in light of their respective contributions. Moreover, the principles of equity and efficiency should be complied with during the utilization of cooperation and development fund and the internal mutual fund, while members achieving extraordinary business results and remaining active in unification and cooperation should be given preference.

\section{REFERENCES}

1. Yuan Peng. Analysis on the development of farmers' professional cooperatives_-Taking the dairy cooperative association of Miyun County in Beijing as an example ,J. Chinese Rural Economy, 2008 (8):pp.44-51

2. Jeffrey S. Royer. Karantininis, J. Nilsson (Eds.). Vertical Markets and Cooperative Hierarchies [M]. Dordrecht: The Netherlands, 2007:169-194.

3. Liu Yuxiang, Research of members' will for cooperative joint development_—based on Anhui and Jiangxi Data, J. Shanxi Agric. Univ.(Social Science Edition),No.2 Vol.16,2017.

4. Kong Xiangzhi,Yue Zhenfei,Zhang Chen. The Nature of Uniting Co-ops-Interpreting Transaction Cost with Empirical Analysis, Journal of Xinjiang Normal University(Philosophy and Social Sciences), No.1 Vol.39,2018.

5. Sheng Zhaohan,Xiao Tiaojun. The mathematical analysis of enterprise group management decision [M].Beijing : China Machine Press,2002,pp.69-71.

6. The study delegation of All China Federation of Supply and Mardeting Cooperatives, The research report on the reform and practice of the governance structure and modern operating system of Bulgarian cooperatives,2019. unpublished.

7. Mei Fuchun,Huang Xiao,Huang Song. Economic analysis of motive force and obstacles of farmers' specialized cooperative association, Journal of Henan Agricultural University, No.4 Vol.54,2020. 